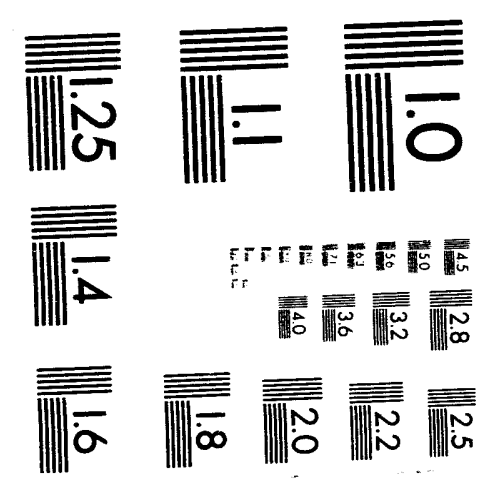



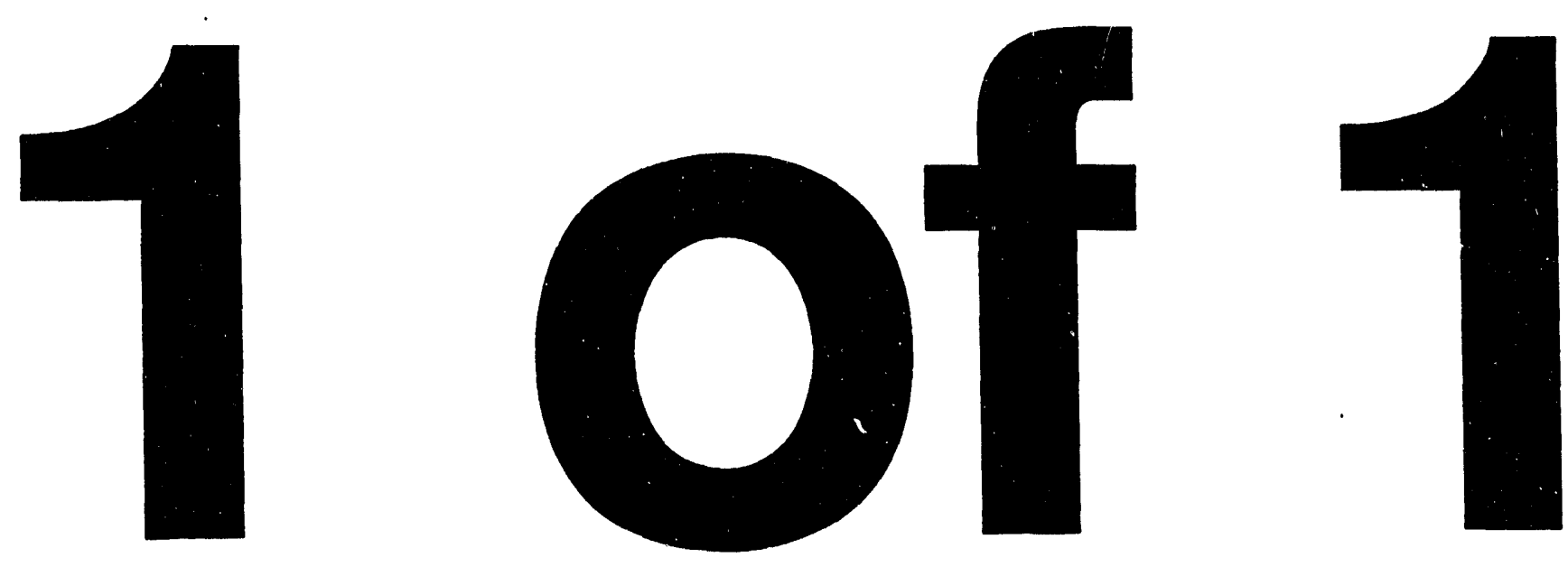


\title{
DEVELOPMENT OF AN ADVANCED, CONTINUOUS MILD GASIFICATION PROCESS FOR THE PRODUCTION OF CO-PRODUCTS
}

\author{
Quarterly Technical Progress Report \\ for the Period April - June 1988
}

by

Robert 0. Ness, Jr., Research Supervisor

JuTy 1988

Work Performed Under DOE METC Contract No. DE-AC21-87MC24267

for

U.S. Department of Energy

Office of Fossil Energy

Morgantown Energy Technology Center

Morgantown, West Virginia

by

University of North Dakota

Energy and Mineral Research Center

Grand Forks, North Dakota

\section{DISCLAIMER}

This report was prepared as an account of work sponsored by an agency of the United States Government. Neither the United States Government nor any agency thereof, nor any of their Government. Neither the United States Goyes, makes any warranty, express or implied, or assumes any legal liability or responsiem bility for the accuracy, completeness, or usefulness of any inforist infringe privately owned rights. Referprocess disclosed, or recific commercial product, process, or service by trade name, trademark, ence herein to and necessarily constitute or imply its endorsement, recom-

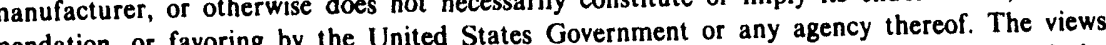
and opinions of authors expressed herein do not necessarily state or reflect those of the United States Government or any agency thereof. 


\section{TABLE OF CONTENTS}

Page

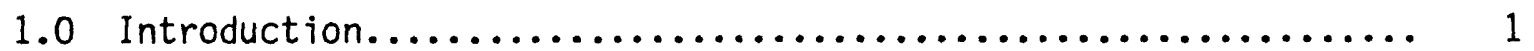

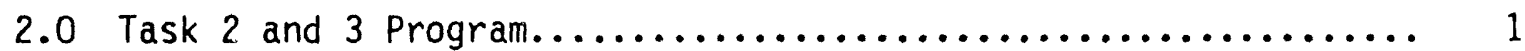

2.1 Task 2 - Goals and Objectives......................... 1

2.2 Task 2 - Test Plan.................................. 2

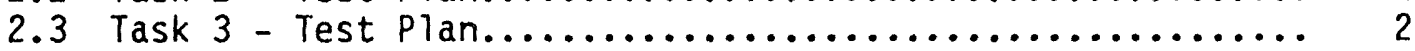

2.3.1 AMAX Char Upgrading Test Program............... 2

2.3.2 Pelletec Test Program....................... 2

3.0 Equipment Modification.............................. 3

4.0 Results from Test Program........................... 6

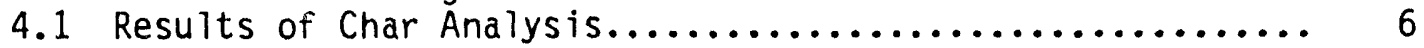

4.2 Results of Condensable Analysis.................... 7

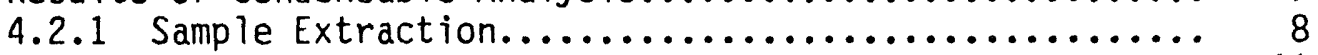

4.2.2 Condensable Analytical Improvements.............. 11

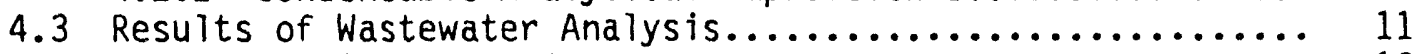

4.4 Results of Gas Analysis.......................... 12

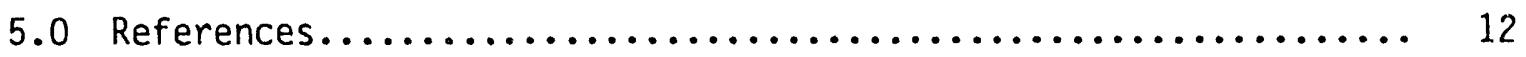

Appendix A -- Draft Test Plan - Task 2..................... A1

Appendix B -- Draft Test Plan - Task $3 \ldots \ldots \ldots \ldots \ldots \ldots \ldots \ldots \ldots \ldots$ B1

Appendix C -- Draft Test Plan - Pelletec Char Testing............. C1 


\section{LIST OF FIGURES}

Figure

Page

1 One-pound/hour continuous pressurized fluid bed reactor (CFBR) schematic.................................. 3

2 Equipment floor plan for mild gasification microlaboratory...... 4

3 Isometric view of mild gasification microlaboratory........... 5

4 Extraction and analys is of mild gasification condensable products -- Scheme 2 ................................ 7

5 Proton NMR spectrum of condensables from the Eagle Butte coal.... 10

A1 Preliminary schematic for the extraction and analysis of mild gasification product............................ A6

C1 Relationship between production costs of mild gasification

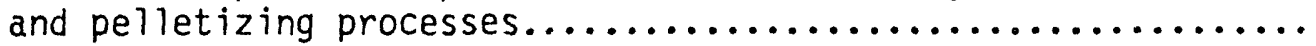




\section{LIST OF TABLES}

\section{Table}

Page

1 Proximate Analysis of Eagle Butte Coal and Char............... 6

2 Condensable Products from Eagle Butte Coals................. 9

3 Results of Laboratory Analyses of Wastewater Generated During Mild Gasification of Eagle Butte Coal....................... 11

4 Gas Analysis Data Sheet.............................. 13

A1 EMRC Proposed Mild Gasification Test Matrix (1.-Found/Hour Cont inuous Fluid Bed Reactor (CFBR) $\ldots \ldots \ldots \ldots \ldots \ldots \ldots \ldots \ldots$ A2

A2 Process Validation and Char Production in the EMRC

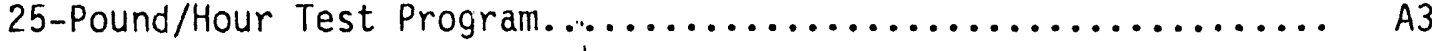




\section{DEVELOPMENT OF AN ADVANCED, CONTINUOUS MILD GASIFICATION PROCESS FOR THE PRODUCTION OF CO-PRODUCTS}

\subsection{INTRODUCTION}

The Morgantown Energy Technology Center (METC) of the Department of Energy (DOE) is investigating a process concept called "Mild Gasification" in which rapid devolatilization of coal under mild conditions of temperature and pressure would yield three product slates: a low- or medium-BTU gas, a valuable hydrocarbon condensate, and a reactive char. To determine the preferred characteristics, as well as a market potential, METC has issued contracts to perform an investigation of process development options of an "Advanced, Continuous Gasification Process for the Production of Co-Products."

The ongoing objr -tive of this program is to develop a continuous mild gasification process which will produce a product mix that optimizes process economics. In order to provide the incentive for private industry to commercialize the process, it is necessary to demonstrate yields and qualities in a versatile continuous process development unit (PDU). This unit must be capable of assessing both coal- and process-specific effects in a costeffective and timely manner. Based on literature reviews and experimental verification, a data base will be developed correlating coal and process parameters with product characteristics. This will provide process developers with the information necessary to derive site-specific economics which will be crucial for the commercialization of the mild gasification process.

The literature review and market assessment has been completed and submitted to METC under Task 1 of the program. Under Task 2, coal-specific tests are being conducted on three AMAX coals: Chinook, an Indiana \#3 bituminous coa7; Delta, an Illinois \#6 bituminous coal; and Eagle Butte, a Wyodak subbituminous coal. Various methods of char upgrading are being conducted by AMAX R\&D of Golden, Colorado. The upgraded char is then combined with iron ore and tested for pig iron production under an AMAX subcontract to

Pellet Technology Corporation of Marquette, Michigan. In addition to the test program, process development and scaleup information is being developed for a 1 ton/hr pilot plant unit.

\subsection{TASK 2 AND 3 PROGRAM}

\subsection{Task 2 - Goals and Objectives}

The goals for the first quarter of Task 2 included:

1. Development and submission of the test plan for Task 2.

2. Modification of the existing mild gasification system for use in the program.

3. Commencement of the test program.

4. Development of analytical methods for char, liquids, and gas. 
A1l of the objectives for the first quarter have been met, and the program is on schedule. Several shakedown tests were made, and one test was completed with full material balance.

\subsection{Task 2 - Test Plan}

The test plan for Task 2 is found in Appendix A. The program includes tests with the following parameters:

1. Effect of coal type (Indiana \#3, Illinois \#6, Wyodak).

2. Temperature $\left(500^{\circ}\right.$ to $\left.700^{\circ} \mathrm{C}\right)$.

3. Pressure (0 to $50 \mathrm{psig})$.

4. Solid residence time (minutes) and heat-up rate.

5. Coal particle size ( -8 mesh to 70 percent -200 mesh).

6. Effect of gaseous environment (steam, $\mathrm{CO}_{2}$, or simulated product flue gas).

These tests will examine areas of particular importance for economic assessment, operability performance, and scaleup data. Only those tests that are shown to be pertinent for scaleup will be performed. Each matrix will determine the tests to be performed in the next set of tests.

\subsection{Task 3 - Test Plan}

\subsubsection{AMAX Char Upgrading Test Program}

The test plan for Task 3 is found in Appendix B. The program includes tests in the following areas:

1. Calcining of the char to reduce volatiles to below $10 \%$.

2. Physical cleaning based on flotation, gravity, or high-intensity magnetic separation.

3. Low-temperature chemical cleaning using water washing after leaching with caustic/acid.

The calcining tests will only be necessary if the results from the pellet production tests indicate that the volatile content of the char must be below $10 \%$. The other methods will explore the effectiveness of the cleaning methods on product quality. The results can then be taken into account in the economic assessment of the process.

\subsubsection{Pelletec Test Program}

The test plan for the testing of the char for pig iron production is shown in Appendix $C$. There are three char characteristics to be studied. These include: 
1. Volatile matter content,

2. Ash content, and

3. Sulfur content.

The study will determine the effect of these characteristics on pellet hardness, reduction rates of char-iron oxide agglomerates, melting characteristics, and quality of resulting iron.

\subsection{EQUIPMENT MODIFICATION}

Figure 1 provides a schematic of the $1-1 \mathrm{~b} / \mathrm{hr}$ continuous fluid bed reactor (CFBR). Several modifications were made to the unit over the past three months. These included moving the unit to another location to facilitate the run schedule and sample collection and analysis. Figures 2 and 3 show the room in which the unit is currently located. The unit is located in a totally enclosed room which has an air exchange in excess of once every three minutes. A hood is located in the room for char and condensable sampling. A new control and data acquisition system has been installed to provide on-line material balance data as well as computer control and data historians, software that records data in a specific format. This allows for fast data reduction with a minimal need for labor requirements.

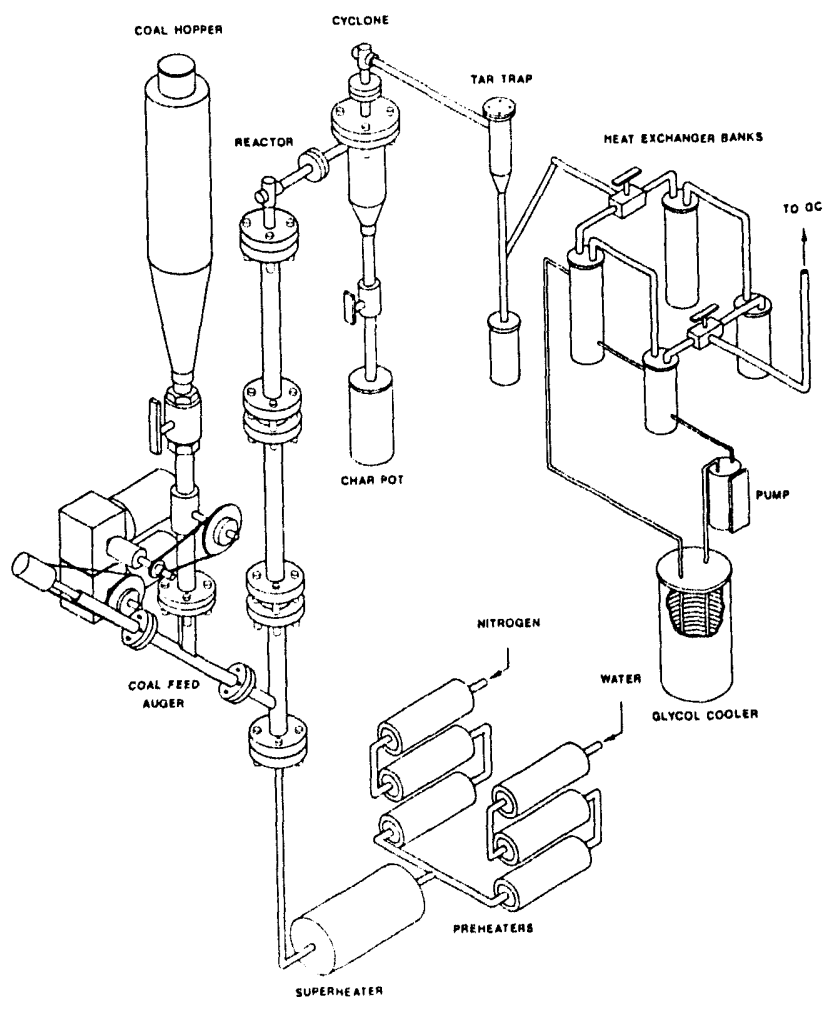

Figure 1. One-pound/hour continuous pressurized fluid bed reactor (CFBR) schematic. 


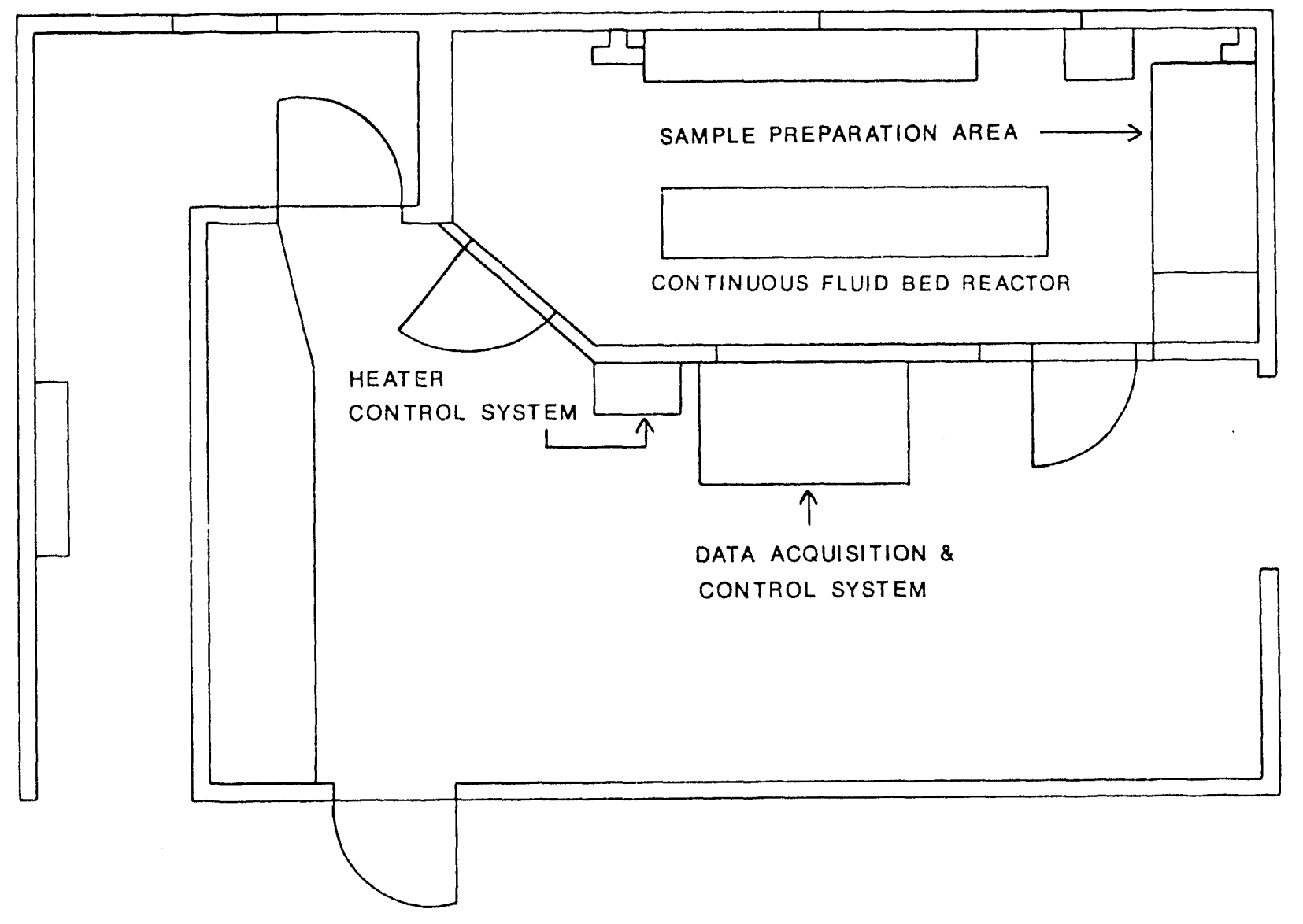

Figure 2. Equipment floor plan for mild gasification microlaboratory. 


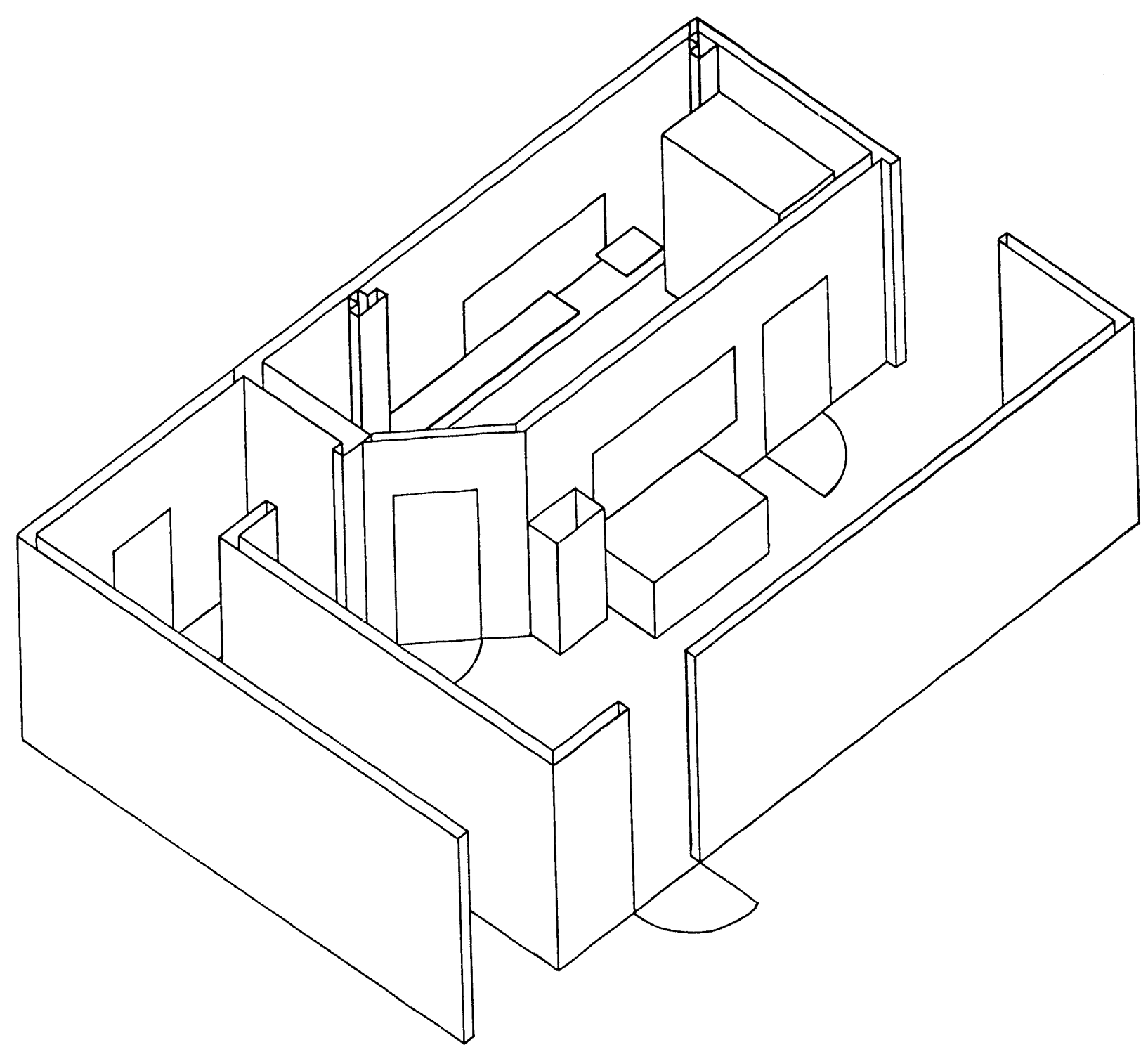

Figure 3. Isometric view of mild gasification microlaboratory. 
Modifications were made to the reactor itself by replacing wraparound bead heaters on each section with clam heaters. This will provide greater reliability and faster turnaround if a heater burns out. All thermocouples were rewired from Type $J$ to Type $K$, since a new data acquisition system is being used and the Type $K$ couples are more accurate and reliable at the temperatures being tested. A new condenser system with tar knockout has been added. This should permit faster and more accurate sampling techniques. Stabilization techniques such as nitrogen purges for the char and acid addition for the condensables can now easily be used with the system. These techniques will decrease surface oxidation of the char and repolymerization of condensables.

\subsection{RESULTS FROM TEST PROGRAM}

Several tests made during the equipment shakedown were conducted on lignite and subbituminous and bituminous coals. The results from the shakedown tests were reported previously (1). One test with a complete material balance was conducted on the Eagle Butte subbituminous coal. All tests were conducted with a $2: 1$ steam-to-coal ratio, at $650^{\circ} \mathrm{C}$, and under atmospheric pressure.

\subsection{Results of Char Analysis}

Table 1 shows the proximate analys is for the char as compared to the coal feed data. The coal was air-dried prior to introduction into the reactor. This was necessary for proper feeding, which is somewhat limited due to the small size of the CFBR. The original coal moisture was $30.68 \%$. It was then dried to 22.10\%. After processing, the volatile content was reduced from $46.40 \%$ to $11.93 \%$ and $13.56 \%$ for the respective char sizes on an MAF basis.

\section{TABLE 1}

\section{PROXIMATE ANALYSIS OF EAGLE BUTTE COAL AND CHAR}

\begin{tabular}{|c|c|c|c|c|c|c|c|}
\hline & \multirow{2}{*}{\multicolumn{3}{|c|}{ Coal }} & \multicolumn{2}{|c|}{ Char } & \multicolumn{2}{|c|}{ Char } \\
\hline & & & & \multicolumn{2}{|c|}{$8,12,20,25$ Mesh } & \multicolumn{2}{|c|}{$35,50,-50$ Mesh } \\
\hline Eagle Butte Coal & $\begin{array}{l}\text { As Mined } \\
(\not) \\
\end{array}$ & $\begin{array}{l}\text { Air- } \\
\text { Dried } \\
(\not) \\
\end{array}$ & $\begin{array}{l}\text { Moist/Ash } \\
\text { Free (q) }\end{array}$ & $\begin{array}{l}\text { As Det. } \\
(\%) \\
\end{array}$ & $\begin{array}{l}\text { Moist/Ash } \\
\text { Free (b) }\end{array}$ & $\begin{array}{c}\text { As Det. } \\
(\not) \\
\end{array}$ & $\begin{array}{l}\text { Moist/Ash } \\
\text { Free (\%) } \\
\end{array}$ \\
\hline \multicolumn{8}{|l|}{ Proximale Analysis: } \\
\hline Moisture & 30.68 & 22.10 & $N / A$ & 12.28 & $N / A$ & 7.89 & $N / A$ \\
\hline Volatile Matter & 33.66 & 34.06 & 46.40 & 9.50 & 11.93 & 11.34 & 13.56 \\
\hline Fixed Carbon (IND) & 30.73 & 39.32 & 53.60 & 70.13 & 88.06 & 72.27 & 86.43 \\
\hline Ash & 4.93 & 4.51 & $N / A$ & 8.07 & $N / A$ & 8.48 & $N / A$ \\
\hline
\end{tabular}


The char volatile content is higher for the smaller particle sizes because the material becomes entrained and leaves the bed faster than the larger particles. Apparently, the char bed was still developing in the reactor, because only a $30 \%$ yield was achieved during the one-hour test period. Also, it was determined that water-gas shift gasification was occurring due to the high hydrogen content of the product gas. This would also account for the lower char yields.

\subsection{Results of Condensable Analysis}

Water and condensable products were collected, separated, and analyzed according to the analytical scheme depicted in Figure 4 . This scheme is slightly different than previously reported. The difference is in the handling of Residue 2 which was previously treated with methylene chloride.

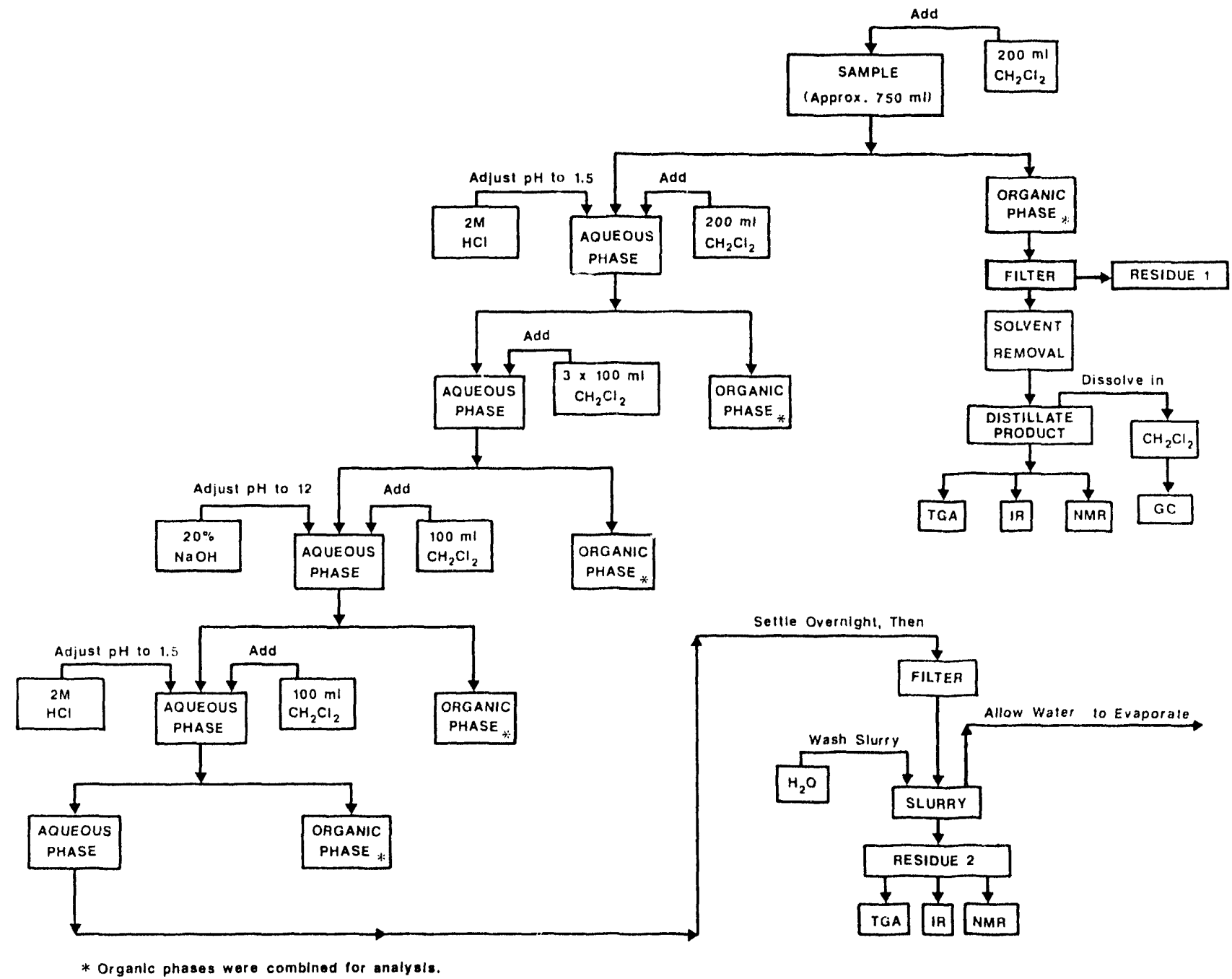

Figure 4. Extraction and analys is of mild gasification condensable products -- Scheme 2 . 
The separation is based on the extraction of the condensable organics from the water phase using methylene chloride. The methylene chloride is then evaporated to obtain the weight of condensable organics. The organics are then analyzed to determine their physical and chemical composition using thermal gravimetric analysis (TGA) techniques, gas chromatography (GC) coupled to a flame ionization detector (FID) and a mass spectrometer for compound separation and identification, a $200 \mathrm{~Hz}$ proton nuclear magnetic resonance spectrometer (H-NMR), and elemental analysis techniques. Prior to analysis, an insoluble material sometimes formed in either the methylene chloride phase (Residue 1) or in the water phase, (Residue 2). This material was removed by filtration and analyzed. Both residues were soluble in base, indicating that they are not coal dust but polymerized products. Catechol is one compound that is known to readily polymerize and precipitate. In future tests, the workup procedures will be modified to attempt to stabilize the samples from repolymerization.

The data for the condensables obtained during the mild gasification of Eagle Butte coal is presented in Table 2. A total of $13.7 \mathrm{~g}$ of organic material were recovered from the water phases as condensables in the coal test. This indicates only a $4 \%$ yield of condensables based on MAF coal fed, which would evidence a large amount of gasification and tar cracking. Preliminary GC data for the Eagle Butte coal indicates the presence of more than 300 compounds, many of which are larger aromatics.

The comparable NMR spectrum for the distillate from the coal indicates a more complex mixture of compounds, as shown in Figure 5 . The broadening of the aromatic proton region at over $8.5 \mathrm{ppm}$ indicates the presence of large aromatic ring systems. The greater complexity between 2.3 and $3 \mathrm{ppm}$ indicates that the aliphatic alkyl side chains are also complex.

The elemental data of Table 2 substantiates these results. The low hydrogen content of the Eagle Butte distillate indicates that it is highly aromatic. The small amount of ash observed may be due to analysis error or to salts added during the extraction of the distillates from water. The residue sample collected from the water phase of the test was washed with water to remove salts and is being analyzed.

\subsubsection{Sample Extraction}

The following steps, as depicted in Figure 4, were followed in the sample extraction process:

1. The total as-received sample containing water and organic condensables was extracted with methylene chloride solvent.

2. The sample was acidified and extracted again.

3. The sample was basified and extracted.

4. The sample was acidified and extracted once more. 
TABLE 2

CONDENSABLE PRODUCTS FROM EAGLE BUTTE COALS

\section{Eagle Butte Subbituminous}

Total Weight of Sample

Total Condensables + Polymer

Water (by Difference)
$1284.0 \mathrm{~g}$

$13.7 \mathrm{~g}$

$1270.0 \mathrm{~g}$

\begin{tabular}{|c|c|}
\hline $\begin{array}{l}\text { Condensables } \\
\text { Composition, }<325^{\circ} \mathrm{C} \\
\text { Phenol } \\
\text { Cresol } \\
\text { Cresol } \\
C_{2} \text {-Phenol } \\
\text { Naphthalene }\end{array}$ & ${ }_{N A^{2}}^{10.5 g}$ \\
\hline Condensables $>325^{\circ} \mathrm{C}$ plus ${ }^{b}$ & $3.0 \mathrm{~g}$ \\
\hline $\begin{array}{l}\text { Total Condensables } \\
\text { Elemental Composition } \\
\text { Carbon } \\
\text { Hydrogen } \\
\text { Nitrogen } \\
\text { Sulfur } \\
\text { Other (diff) } \\
\text { Ash (by TGA) }\end{array}$ & $\begin{array}{l}13.5 \mathrm{~g} \\
79.93 \mathrm{wt} \% \\
6.87 \\
0.57 \\
0.54 \\
11.45 \\
0.64\end{array}$ \\
\hline $\begin{array}{l}\text { Organic-Phase } \\
\text { Polymer (Residue 1) }\end{array}$ & $0.1 \mathrm{~g}^{\mathrm{C}}$ \\
\hline $\begin{array}{l}\text { Water-Phase } \\
\text { Polymer (Residue 2) }\end{array}$ & $0.2 \mathrm{~g}^{\mathrm{d}}$ \\
\hline
\end{tabular}

a The GC data has not been completely reduced.

$b$ Determined by TGA techniques.

c The amount of organics present was based on the carbon content.

d This residue was washed to remove salts and is being analyzed in detail. 


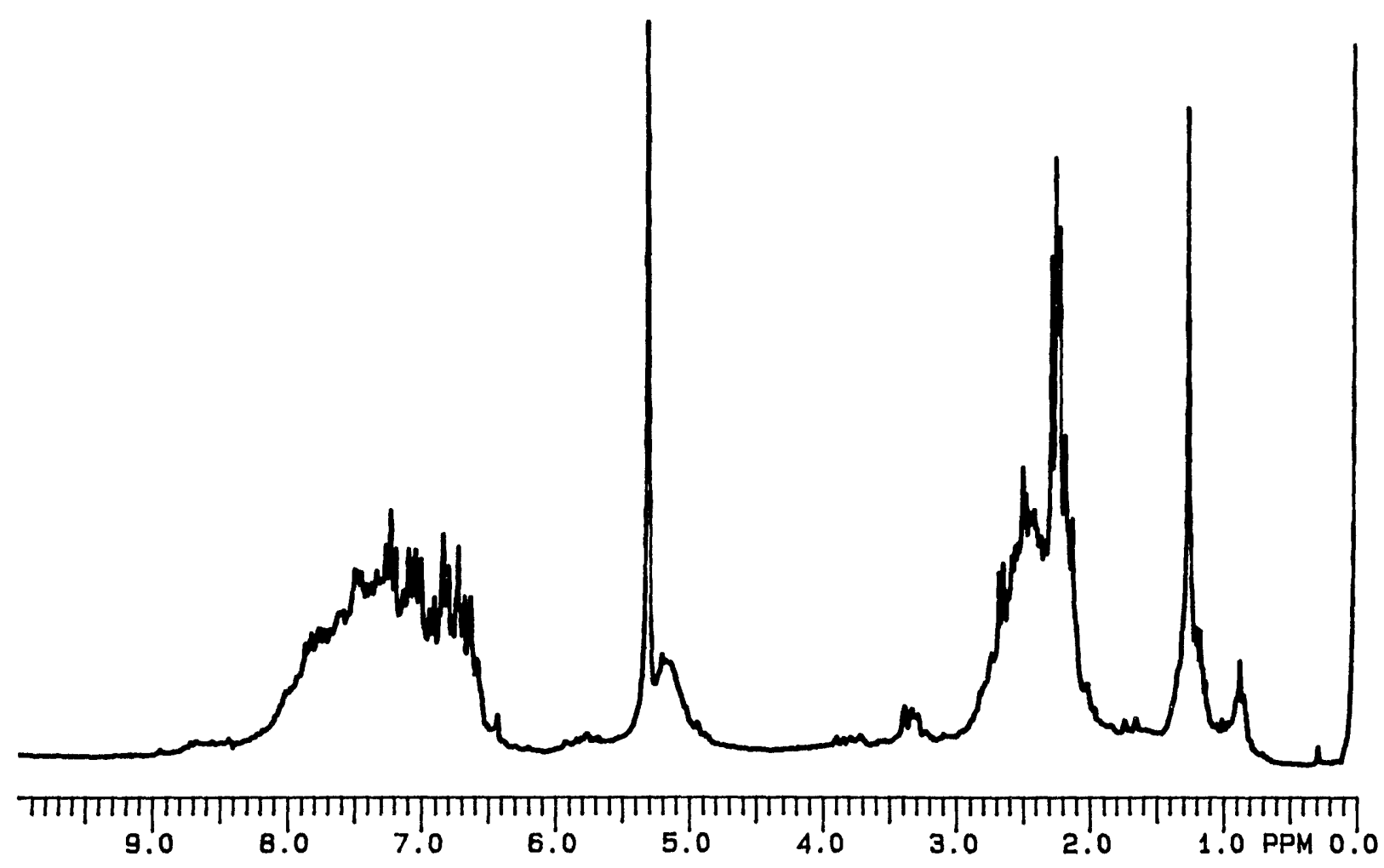

Figure 5. Proton NMR spectrum of condensables from the Eagle Butte coal.

The organic phases (methylene chloride extracts) were combined for subsequent analysis. The total organic phase was then filtered to remove suspended solids, resulting in Residue 1 . Suspended solids present in the water phase were removed by filtration to give Residue 2 .

In order to determine the total weight of organic components dissolved in the methylene chloride, it was necessary to remove the methylene chloride by evaporation. The evaporation was accomplished using a "Rotovap" rotary evaporation apparatus. Before subjecting the sample to evaporation, a small aliquot (about $15 \mathrm{~mL}$ ) was set aside for analysis. The remaining sample (about $900 \mathrm{~mL}$ ) was then split to provide two duplicate samples and introduced into the Rotovap for methylene chloride removal. Following evaporation of the methylene chloride, the weights of the two organic phase samples were combined to provide the yield of condensable organic product. To determine whether any organic components had evaporated along with the methylene chloride, a sample of the organics was redissolved in methylene chloride and analyzed with GC. The resulting chromatogram was compared to a chromatogram (obtained using identical chromatographic conditions) of the organic phase present in the small aliquot removed from the bulk of the sample prior to evaporation. The comparison indicated that essentially none of the condensable product had been lost during evaporation of the methylene chloride. 


\subsubsection{Condensable Analytical Improvements}

1. Future improvements to the analysis of condensable compounds -- spiking of samples with a series of alkane standards prior to evaporation is planned to better determine any losses which occur during evaporation.

2. Stabilize products -- stabilizing of diphenolics by acidification to prevent their polymerization is planned. Additional analytical methods such as ion chromatograpy may be required to analyze for catechols, etc.

3. Identifying additional compounds to more fully determine potential uses of the condensable products -- special attention will be given to nitrogenand sulfur-containing compounds.

\subsection{Results of Wastewater Analysis}

A sample of wastewater was submitted to the UNDEMRC waste analysis laboratory for partial chemical characterization. Results of the analyses performed are presented in Table 3. The wastewater sample was filtered prior to analysis; therefore, the results represent the water-soluble fraction of organic contamination. These results are typical of coal gasification wastewater condensates for the constituents analyzed.

TABLE 3

RESULTS OF LABORATORY ANALYSES OF WASTEWATER GENERATED DURING MILD GASIFICATION OF EAGLE BUTTE COAL

\begin{tabular}{lc}
\hline \multicolumn{1}{c}{ Parameter } & $\begin{array}{c}\text { Concentration } \\
\text { (mg/l, except } \mathrm{pH})\end{array}$ \\
\hline Chemical Oxygen Demand & 12,800 \\
Biochemical Oxygen Demand, 5-day & 2,180 \\
Cyanide & $<1$ \\
Ammonia & 2,470 \\
$\mathrm{pH}$ & 9.04 \\
\hline
\end{tabular}

The chemical oxygen demand (COD) is a measure of the oxygen required to chemically oxidize the organic and sometimes inorganic matter in a wastewater. The COD test does not measure the oxygen required to convert ammonia to nitrites or nitrites to nitrates. Thus, COD is frequently assumed to be the ultimate first-stage biochemical oxygen demand.

The biochemical oxygen demand (BOD) is the amount of oxygen required to biochemically oxidize the organic matter under aerobic conditions. The $\mathrm{BOD}_{5}$ of the mild gasification process condensate was only $2,180 \mathrm{mg} / \mathrm{l}$, as opposed to a $12,800 \mathrm{mg} / \mathrm{l} \mathrm{COD}$. The $10 \mathrm{~W} \mathrm{BOD}_{5}$ value does not necessarily represent high amounts of biologically resistant organic matter in the sample, but is 
probably due to the age of the sample. The sample was not analyzed immediately because the test program was in the shakedown phase. Samples for BOD analysis may degrade significantly during storage between collection and analysis, resulting in low BOD values.

Elevated ammonia concentrations in the mild gasification wastewater sample, along with the high organic content, make the wastewater neither suitable for use as direct cooling tower makeup water nor as discharge to the environment before treatment for organic and ammonia removal.

\subsection{Results of Gas Analysis}

Table 4 shows the gas analysis for the Eagle Butte test. The large hydrogen content in the gas can be attributed to the fact that the gas phase above the char bed was maintained at $700^{\circ} \mathrm{C}$ instead of $650^{\circ} \mathrm{C}$. These conditions promote the water-gas shift reaction which produces a high hydrogen content in the gas stream. The large $\mathrm{N}_{2}$ concentration was a result of the $\mathrm{N}_{2}$ that was fed to the reactor for fluidization purposes.

\subsection{REFERENCES}

1. Ness, Robert 0. "Mild Gasification." Annual Technical Report for the Period Apri1 1, 1987-March 31, 1988, including the Quarterly Technical Progress Report for the Period January through March 1988. Work Performed under DOE METC Cooperative Agreement NO. DE-FC21-86MC10637. May 1988. 
TABLE 4

GAS ANALYSIS DATA SHEET

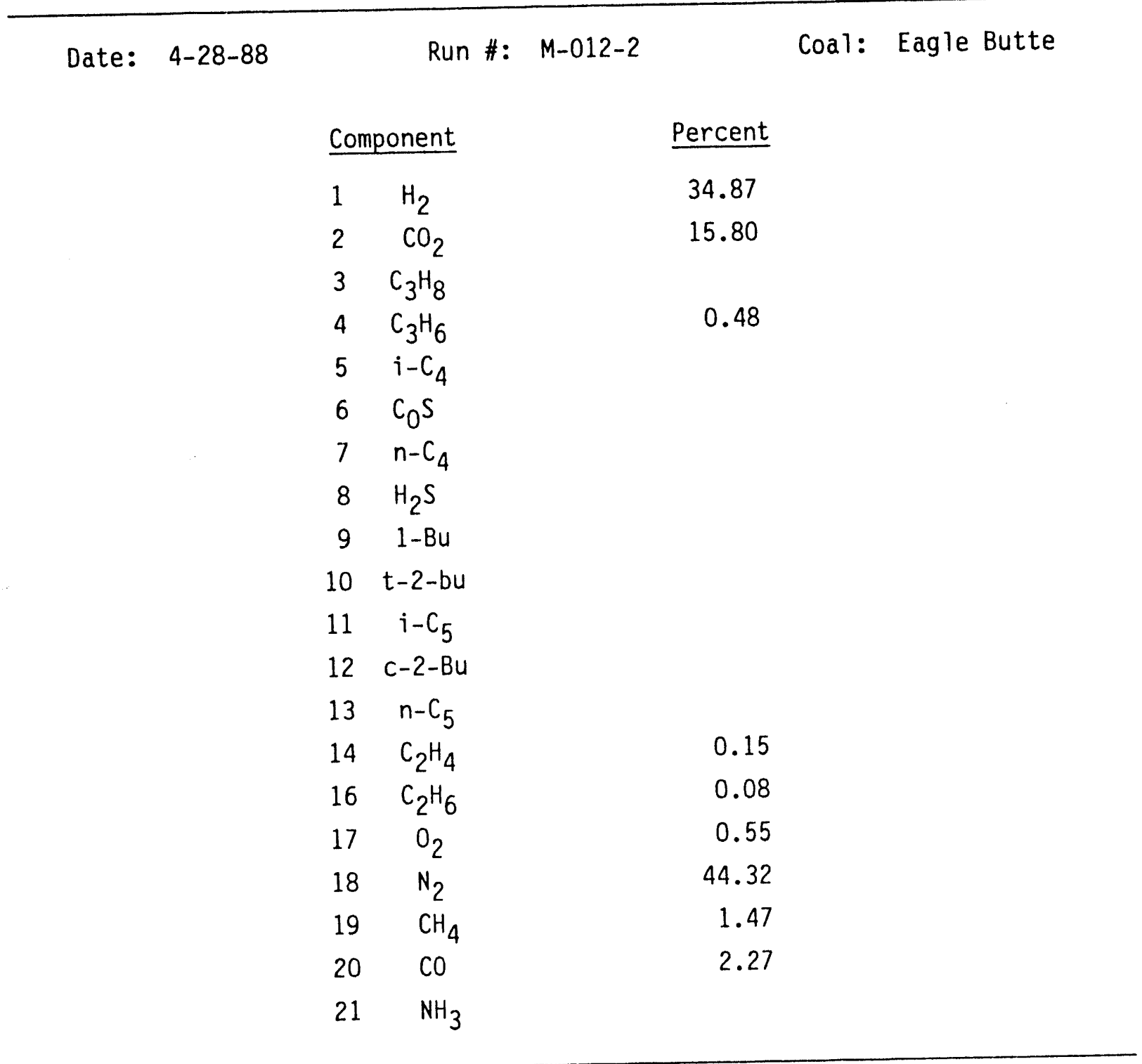


APPENDIX A 


\section{DRAFT TEST PLAN - TASK 2}

\section{Task 2 Bench-Scale Mild Gasification Study}

The Energy and Mineral Research Center (EMRC) will perform the various subtasks of the mild gasification study as discussed below. Results will be discussed with other team members and their suggestions included as appropriate. The technical project officer from METC will be promptly informed about any major findings or problems, and his permission will be obtained before making any major changes in the program.

The goals for this program include:

1. Producing sufficient char at each test point for char upgrading and pellet testing.

2. Determining the effect of volatile content on pellet and steel characteristics, condensable quality, and gas quality. (What is the upper limit of percent volatiles until the pellet loses integrity?)

3. Determining the effect of sulfur in the char on steel production.

4. Determining operational characteristics and engineering data of the system for scaleup.

These goals will be accomplished by investigating points through the following suggested program.

\section{Subtask 2.1 Test Plan for Mild Gasification Study}

A preliminary design, utilizing available equipment and findings from the current EMRC mild gasification project, will be suggested. The following parameters will be included:

a. Effect of coal type (Indiana \#3, Illinois \#6, Wyodak)

b. Temperature $\left(500^{\circ} \mathrm{C}\right.$ to $\left.700^{\circ} \mathrm{C}\right)$

c. Pressure (0 to 50 psig)

d. Solid residence time (minutes) and heat-up rate

e. Coal particle size ( -8 mesh to 70 percent -200 mesh)

$f$. Effect of gaseous environment (steam, $\mathrm{CO}_{2}$, product, or flue gas)

These tests will investigate areas of particular importance for economic and operability performance only. The suggested list does not indicate that al1 tests must be conducted. Thus the test program can begin at the COTR's notification.

A suggestion for the generalized test program, as shown in Table Al, has been developed for existing EMRC equipment. Matrix 1 will determine product distribution as a function of coal, temperature, and residence time. Matrix 2 will determine the effect of pressure on yields and whether temperature and residerice time play a more important role than pressure. Matrix 3 will determine the relationship of coal size, temperature, and residence time. Matrix 4 will test the effect of the reaction atmosphere. Matrix 5 will 
TABLE A1

EMRC PROPOSED MILD GASIFICATION TEST MATRIX

(1-POUND/HOUR CONTINUOUS FLUID BED REACTOR (CFBR))

\section{Matrix 1 (Steam Atmosphere)}

3 Coals (Indiana \#3, I1 linois \#6, Wyodak)

3 Temperatures $\left(500^{\circ} \mathrm{C}, 600^{\circ} \mathrm{C}, 700^{\circ} \mathrm{C}\right)$

3 Residence Times (20, 40, 60 minutes)

$\overline{27}$ Data Points

(Matrices 1 and 2 will be performed as 25-pound/hour PFBG runs)

Goal: Produce a variety of char with different volatile contents for char upgrading and pellet testing.

Matrix 2 (Steam Atmosphere, Best Coal from Matrix 1)

3 Pressures (atm, 25 psi, 50 psi)

3 Temperatures $\left(500^{\circ} \mathrm{C}, 600^{\circ} \mathrm{C}, 700^{\circ} \mathrm{C}\right)$

3 Residence Times

$\overline{27}$ Data Points

Goa 1: Verify that an increase in reactor pressure does not significantly affect product distribution.

Matrix 3 (Steam Atmosphere, Best Conditions from Matrices 1 and 2)

3 Coal Sizes $(-8,-100,-200$ mesh)

3 Temperatures $\left(500^{\circ} \mathrm{C}, 600^{\circ} \mathrm{C}, 700^{\circ} \mathrm{C}\right)$

$\frac{3}{27}$ Residence Times

$\frac{3}{27}$ Data Points

Goal: Optimize coal feed size in fluid bed system.

Matrix 4 (Best Conditions from Matrices 1, 2, and 3.)

3 Types (Steam, $\mathrm{CO}_{2}$, product gas composition)

3 Temperatures $\left(500^{\circ} \mathrm{C}, 600^{\circ} \mathrm{C}, 700^{\circ} \mathrm{C}\right.$ )

$\frac{3}{27}$ Residence Times

27 Data Points

(Matrices 3 and 4 will be performed as 25-pound/hour PFBG runs)

Goal: Determine the amount of recycle flue gas that can be used and its effect on product distribution. 
TABLE A1 (continued)

Matrix 5 (Optimal Char Removal Method)

Repeat of Matrix 1 except remove char from top of bed instead of using cyclone separation. (Discussed in section describing Subtasks 2.2 and 2.3, Reactor Design, Construction, and Modification.)

Goal: Determine the optimum method of char removal: cyclone or top of the bed.

provide information about the method of char removal. Steam will be used in the first three matrices, and product gas and carbon dioxide will be tested in the last matrix. A full material balance and analytical characterization will be performed for each test.

A11 testing on the 25-pound/hour unit is optional and will depend on the amount of modification necessary to the existing equipment. Dependent on the results from the 1-pound/hour continuous unit tests, four runs may be planned with the 25-pound/hour unit as outlined in Table A2. Two runs will be made after the optimum conditions for two coals are determined in Matrix 1 . The bulk char material will be sent to Pellet Technology Corporation (Pelletec) or AMAX Research and Development Center (AMAX) for use in the ir programs. Actual testing of the char for pelletizing and steel production will be the responsibility of Pelletec. These tests are not part of the mild gasification work plan.

\section{TABLE A2}

PROCESS VALIDATION AND CHAR PRODUCTION

IN THE EMRC 25-POUND/HOUR TEST PROGRAM

Runs 1 and 2

Best condition for Matrix 1. Bulk production of char to be sent to Pelletec or AMAX.

Run 3 Best conditions for Matrices 1-4. Bulk production for Pelletec or AMAX.

Run 4 Best conditions for Matrices 1-4. Bulk production for Pelletec or AMAX. 
Subtasks 2.2 and 2.3 Reactor Design, Construction, and Modification

EMRC has several units available for mild gasification work, including a 1-pound/hour continuous fluidized bed reactor (CFBR) and a 25-pound/hour pressurized fluid bed gasifier. The CFBR is currentiy in the GFETC's fast fluid bed carbonizer mode. The first segment of testing will occur by removing the char and volatiles through the top of the reactor. While this phase of the process development work is continuing, the char removal leg that is used in the FMC COED process will be built. The CFBR was designed with interchangeable sections so that the integration of a drop leg does not require modification to the existing system. In fact, the system was designed to allow for top feed, bottom feed, and char removal from the bottom or top of the bed. The system changes occur simply by exchanging sections of the reactor.

Four units are used mainly in analytical research and will be used for screening and developing an initial data base on a variety of coals if concurrence is reached with the COTR that correlation with the CPU can be developed. These units are the three TGA units and the pyrolysis unit coupled to a GC/FID. The main unit will be the 1-pound/hour continuous fluid bed reactor. The preliminary screening research will be done on this unit. The bulk production runs will be done on the EMRC 25-pound/hour pressurized fluid bed gasifier if major modifications are not necessary. If major modifications are necessary, this option will be dropped and bulk production will be delayed until Task 4.

\section{Subtask 2.4 Mild Gasification Tests}

A series of tests will be conducted according to the approved plan developed under Subtask 2.1 to investigate the mild gasification operating parameters. Each run will be accompanied by a complete material balance and routine analytical workups. The char will be split into two samples, of which one will be sent to Pelletec or AMAX for char upgrading or pelletizing studies.

\section{Subtask 2.5 Product Characterization and Data Analysis}

Because of the variety of products, a number of analytical tests are required. Data from these tests will also be compared with the large, inhouse data base. This will allow direct comparison with complementary or competing technologies and provide a more complete picture of the process. The largest data bases available will be from the EMRC Hydrogen Production and Jet Fue 1 programs.

The following tests are recommended for characterization of the products and will be amended based on results of the Task 2 surveys and concurrence of the COTR.

Gas Analysis

1. Gas analysis, including $\mathrm{H}_{2}, \mathrm{CO}, \mathrm{CO}_{2}, \mathrm{CH}_{4}, \mathrm{C}_{1}-\mathrm{C}_{4}, \mathrm{NH}_{4}$, and $\mathrm{H}_{2} \mathrm{~S}$ 


\section{Gas Analysis}

1. Gas analysis, including $\mathrm{H}_{2}, \mathrm{CO}, \mathrm{CO}_{2}, \mathrm{CH}_{4}, \mathrm{C}_{1}-\mathrm{C}_{4}, \mathrm{NH}_{4}$, and $\mathrm{H}_{2} \mathrm{~S}$

Condensable Analysis

Figure Al shows an extraction method which we believe will be effective in removing the organics from the aqueous portion of the product.

Char Analysis

1. CHN and Sulfur

2. Moisture Absorption

3. Ash

4. Volatile Content

5. Heating Value

6. Surface Area (BET) (Selected Samples)

7. Combustability (TGA) (Selected Samples)

The aforementioned analyses will be performed on each run on the 1-pound/ hour and 25-pound/hour units and for selected samples from the screening study on the analytical units. Special analyses that will be done on selected samples will include:

Liquid Analysis

1. GC/Mąss Spec

2. NMR ${ }^{2} \mathrm{H}$ and ${ }^{13} \mathrm{C}$

3. Class Separation

Char Analysis

4. Bulk Strength

5. SEM for Determination of Pore Size

6. BET Surface Area Determinations

7. Solid-State NMR

The special analyses will be used to track chemical groups in order to determine where specific fractions appear in the feed material and in the product distribution. This will aid in the understanding of reaction mechanisms and could lead to process improvements.

Optional tests for upgrading the condensables are also recommended. These tests would involve deodorizing and degumming the condensables as preliminary steps prior to distillation. The upgrading steps would include acid/base extraction, solvent extraction, and mild hydrotreating. Equipment is available on site for the process development work. 


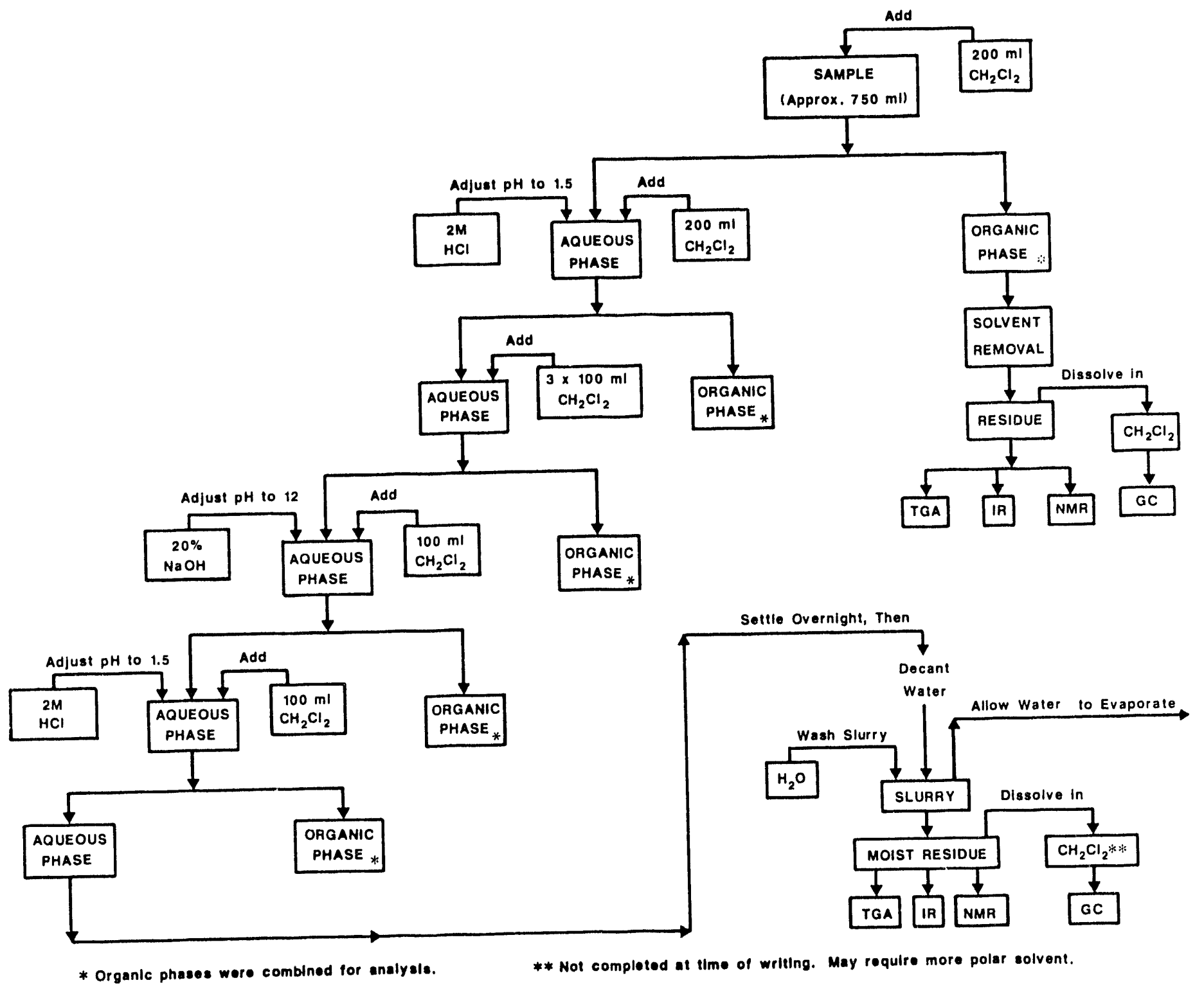

Figure Al. Preliminary schematic for the extraction and analys is of mild gasification product. 


\section{Subtask 2.6 Comprehensive Topical Report}

The results of the mild gasification study (Task 2) will be presented in the form of a comprehensive topical report. It will contain the details of the test plan describing the various operating parameters studied. The pertinent data collected during the program and the results obtained will be presented in the form of summary tables and figures.

The report will discuss the results obtained by testing various operating parameters. It will identify the most effective process and operating conditions determined in the program. Statistical correlation of product yield and quality to coal character and process parameters will be developed. Any major area of process development that needs further investigation will be identified.

The report will also contain detailed plans for performing the optional tasks, including the recommended design of the process development unit and specifications of the operating conditions. 
APPENDIX B 
DRAFT TEST PLAN - TASK 3

Task 3 Bench-Scale Char Upgrading Study

AMAX and EMRC will perform the various subtasks as discussed below and will discuss the results with other team members, including their suggestions as appropriate. The technical project officer from METC will be promptly informed about any major findings or problems, and his permission will be obtained before making any major changes in the program.

\section{Subtask 3.1 Test Plan for Char Upgrading Study}

AMAX and EMRC will develop a test plan for conducting bench-scale studies of the selected upgrading methods. It is anticipated that the methods will fall into three categories:

1. Calcining of the char to reduce volatiles. This upgrading step will be necessary if the volatile matter must be reduced below 10 percent for optimum pelletizing steps. (EMRC)

2. Physical cleaning based on flotation, gravity, or high-intensity magnetic separation. These processes could be applied to preclean the coal feed or to upgrade the char. (AMAX)

3. Low-temperature chemical cleaning using water washing after leaching with caustic/acid. (AMAX)

It is not anticipated that char upgrading is necessary; however, this statement must be verified.

Three methods will be tested for reducing the sulfur, nitrogen, and ash in the char produced by mild gasification. A separate test series will be required to determine the amenability of char upgrading by each method. Since the calcining step has been determined to be an option for char upgrading and was not included in the EMRC original proposal, modification to the Task 3 budget will be necessary. The char, both upgraded and non-upgraded, will be tested by Pellet Technology Corporation for its characteristics for steel production.

The test plan will detail the objectives of each test series, the number of tests planned, a description of the experimental setup to be used and procedures to be followed, the various samples to be collected and analyzed, and data to be recorded. The test variables will be selected based on the literature review and past experience. In the beginning, only one type of char produced under the most preferable mild gasification conditions will be used to determine the relative capabilities of various upgrading methods. Later, the best process at its optimum process conditions for each of the steps will be tested on various types of char to determine the effects of char type, particle size, and severity of mild gasification conditions.

A draft test plan has been submitted to the COTR. Only after his approval will actual work be started. If the results obtained during the test program indicate a need for changing the test plan, such changes will be 
recommended to the COTR in writing and, upon his approval, will be incorporated into the test plan.

\section{Subtask 3.2 Experimental Design}

Based on the test plan developed under Subtask 3.1, a bench-scale unit will be designed to perform the planned char upgrading studies. Since the goal of this study will be a parametric evaluation of selected processes, batch tests on small char samples will be most appropriate.

For the types of physical and chemical cleaning methods envisioned at this time, AMAX has the required basic equipment and instruments. However, it is very likely that modifications may have to be made to the equipment or auxiliary systems in order to perform the tests and collect appropriate samples and test data in an efficient manner.

\section{Subtask 3.3 Fabrication of Experimental Unit}

Upon receiving the DOE COTR's approval of the design developed and submitted under Subtask 3.2, AMAX and EMRC will start fabrication of the test unit for bench-scale char upgrading studies. AMAX and EMRC machine shops are well equipped to perform such fabrication and erection. If considered advantageous to the project, outside contractors or vendors may be used to provide certain units.

The experimental unit will be installed in a separate location to provide a safe environment for the workers, as well as for proper protection of the property purchased specifically for this project.

\section{Subtask 3.4 Char Upgrading Tests}

A series of tests will be conducted according to the approved test plan developed under Subtask 3.1 to investigate physical and/or chemical methods for precleaning the coal feed or upgrading the char produced via mild gasification. As mentioned earlier, probably two or three different methods will be investigated on one char sample to determine the relative capabilities of these methods. The most promising methods, or a flow sheet combining them, will then be investigated to determine the effect of major process variables on the char upgrading results. This information will be used for developing the design of the process demonstration unit under Task 4.

After a process flow sheet has been selected, several samples of char representing different feed materials, mild gasification conditions, and particle sizes will be tested to determine the applicability of the process to various types of char and the effect of char quality on the efficiency of the process. During this phase of the program, at least one test series will be conducted to provide a good mass balance on the entire circuit.

Because of the innovative nature of the process development required, a senior chemist and a senior engineer will be working on this program with the help of experienced technicians who will do more routine things. All of the test conditions and sample logs will be properly controlled, monitored, and recorded. 
Subtask 3.5 Product Characterization and Data Analysis

Based on their experience with characterization of coal for various premium fuel applications, AMAX and EMRC recommend the following characterization of feed char and upgraded char.

o Ash chemistry and fusion temperature.

o Combustability/reactivity by thermogravimetric analysis in oxygen.

o Higher and lower heating value.

o Grindability--Hardgrove, Bond, and stirred ball mill.

o Liberation--Washability test at 48-, 150-, and 400-mesh grind.

o Proximate and ultimate analyses ( $\mathrm{C}, \mathrm{H}, \mathrm{N}, \mathrm{S}, \mathrm{O}, \mathrm{Cl}$, ash, and volatiles).

o Petrographic (microscopic) examination.

Larger samples from selected tests will be returned to UNDEMRC for tests in the diesel or turbine simulators.

Pelletec will receive samples for evaluation of pelletizing and steel production.

Characterization will not be performed on all of the treated samples. For many of them, sulfur and ash analyses will be adequate to determine the upgrading obtained by various methods under various conditions. The final products from various processes will be more thoroughly characterized to perform a comparative evaluation of alternate methods of upgrading.

\section{Subtask 3.6 Comprehensive Topical Report}

The results of the bench-scale char upgrading study (Task 3 ) will be presented in the form of a comprehensive topical report. It will contain the details of the test plan describing the various upgrading methods studied. The experimental setup used in each case will be described, along with the test procedures and test conditions used. The pertinent data collected during the program and the results obtained will be presented in the form of summary tables and figures. Where appropriate, more detailed tables will be included as an appendix.

The report will discuss the results obtained by various processes and correlations developed to predict the effect of process variables on upgrading results. It will identify the most effective process and operating conditions determined in the program. Any major area of process development that needs further investigation will also be delineated.

The report will also contain detailed plans for performing the optional tasks, including the recommended design of the process development unit and specification of the operating conditions for study of char upgrading. 


\section{APPENDIX C}




\section{DRAFT TEST PLAN - PELLETEC CHAR TESTING}

There are two questions that must be answered in order to further develop the economics of the mild gasification-PTC steel making-cogeneration process: the effect of volatile content in the char on the pelletizing process, and the effect of the sulfur content on the quality of steel.

These questions refer to process optimization rather than technological feasibility because the process has been demonstrated. Product verification also needs further development. Product yields must be verified over a variety of processing conditions before process scaleup can occur.

\section{Effect of Volatile Content in the Char on Pelletizing Process}

This data is important since this relationship will affect the optimization of the economics of the process. It has been established that the pelletizing process works with a char volatile content of 10 percent or less. By adding more binder, the volatile content specification for pelletizing may rise. This would reduce the operating temperatures required for mild gasification, thus reducing operating costs. However, this will increase the cost of the pelletizing process. An example of this relationship is shown in Figure C1. A determination of the crossover in the economics for these variables must be done, requiring knowledge of char volatile content as a function of mild gasification operating temperature and char volatile content as a function of pellet strength.

The Effect of Sulfur Content of the Char on the Quality of Steel

Although good quality steel has been produced from coal char, the effect of the sulfur content on the product is not known. By producing char with varying amounts of sulfur and then producing steel from the pellets, this effect can be determined. 


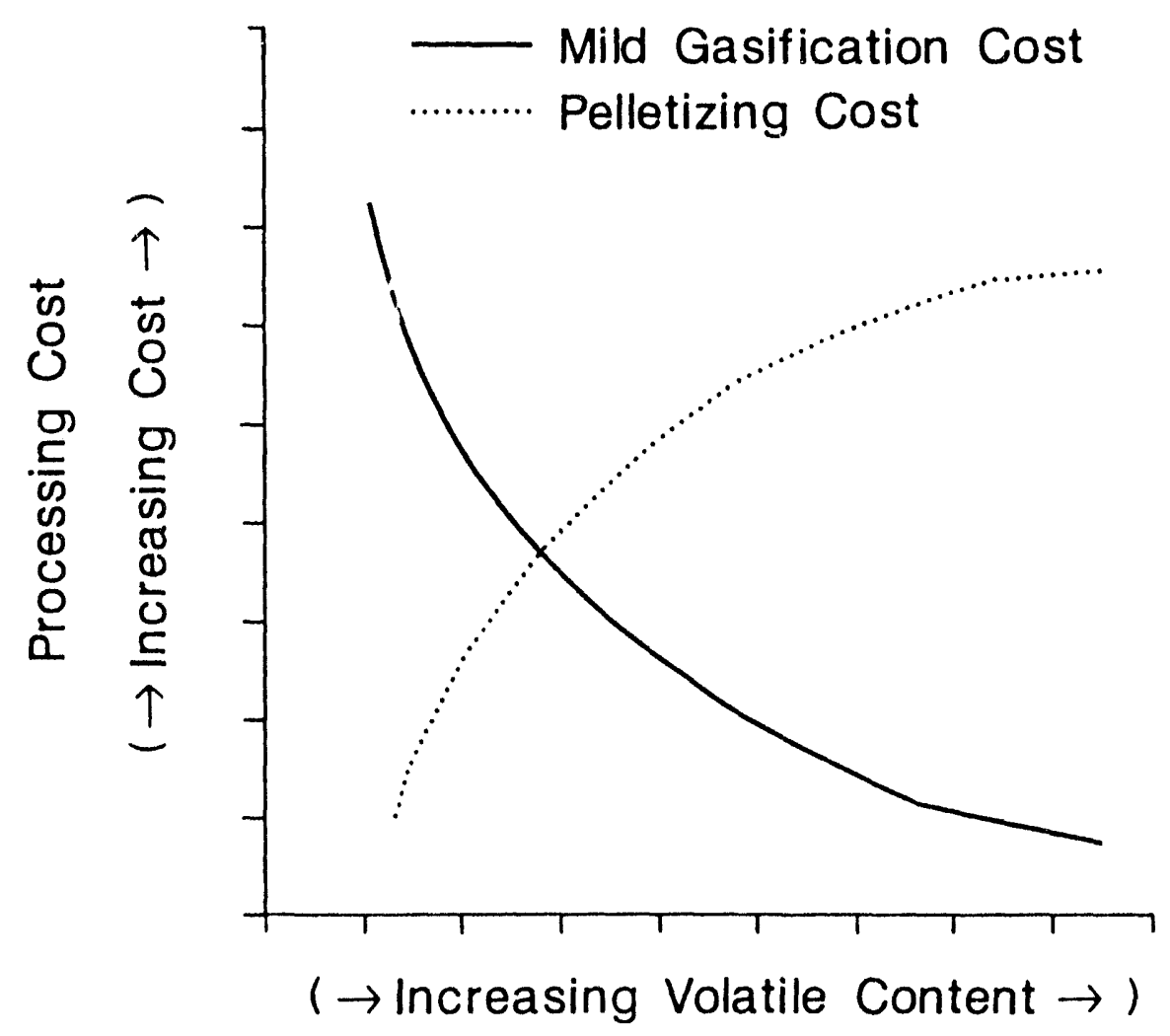

Figure $\mathrm{C1}$. Relationship between production costs of mild gasification and pelletizing processes. 

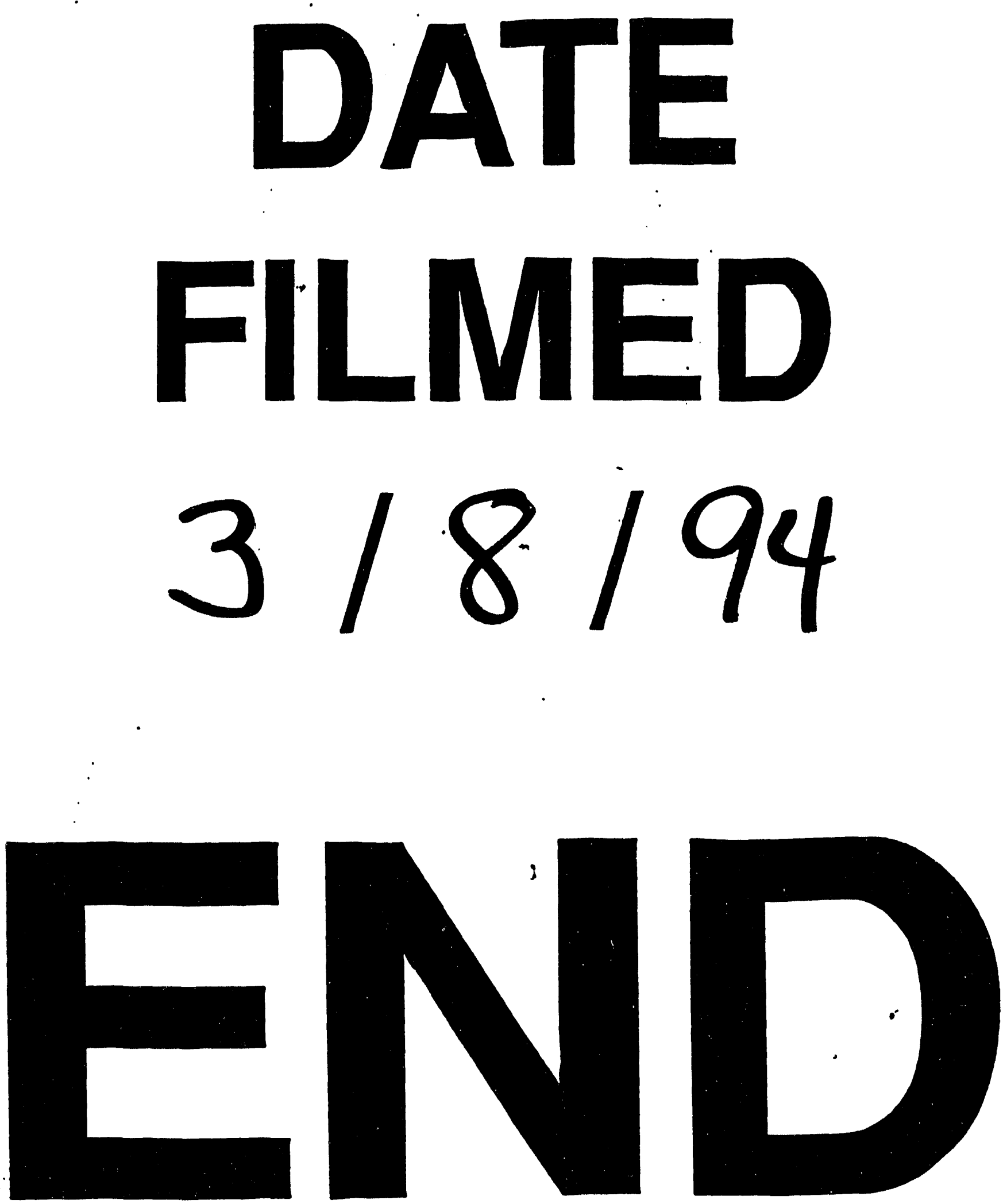
